\title{
People's Perception of the Socio-Cultural and Environmental Impacts of Tourism in Malaysia: A Community-Reflective Study
}

\author{
Prof. Dr. A. H. M. Zehadul Karim \\ BA (Hons), MA (Dhaka); \\ MA (Syracuse, USA); PhD (Syracuse, USA) \\ Certificate in South Asian Studies (USA) \\ Assoc. Prof. Dr. Rohaiza Rokis \\ MHSc. (Kuala Lumpur), \\ MSc. (Stirling), Ph.D (Bristol) \\ Dato' Yahya Awang \\ BSoc.Sc. (USM, Penang), \\ MSoc.Sc. (University of Birmingham, UK) \\ Department of Sociology and Anthropology \\ International Islamic University Malaysia
}

\begin{abstract}
Tourism is considered as the largest service-oriented industry of Malaysia, contributing enormously in economic terms to the GDP (gross domestic product) of the country, delivering employment to a sizeable section of the population, and fostering civic pride, social prestige, and international recognition as a desirable tourist destination. The tourism industry parades the beauty of Malaysian culture abroad as well as it enables people from outside to acquaint with a unique Muslim heritage amidst Malay modernity. Notwithstanding its many blessings, the tourism issue has sparked debate recently necessitating a discourse on a 'rational framework for Malaysian tourism' upon the premise that the benefits of tourism should not only be calculated in economic metrics, rather its demerits should be factored in as well. Under this circumstance, this paper empirically reflects the Malaysian community's perception on the socio-cultural and environmental effects of tourism at the grassroots level.
\end{abstract}

Key Words: Tourism development, Malaysia, community perceptions, socio-cultural and environmental impacts.

\section{INTRODUCTORY BACKGROUND}

Malaysia arguably stands out amongst the kindest nations in the world, being advantageously poised at the gateway to a number of nations going through oceanic trade-routes with a superb eco-natural setting. Owing to its pluralistic culture and roots, it has acquired its own particular customary ethos with concordant combination of the assorted ethnic communities living in an amicable, tranquil and politically stable atmosphere. Because of such serene components, twined with its natural beauty, many individuals from abroad are attracted to this land. Consequently, they often visit as tourists (see Badri bin Hj Masri, 1991). As recently as the year 2013, it is reported that a minimum of 16.7 million international tourists visited Malaysia, ushering - in economic terms - about 30 billion ringgit in foreign currency to the country (see Badruddin et.al. 2006). Thus, it is very likely that the tourism industry, with an objective of securing profit, has been developing rapidly in Malaysia - too quickly for its own good. In any 
case, it cannot be denied that tourism has many negative effects, putting the nation into some social and ecological restraints. To underline the good and bad effects of tourism, exhaustive research and reviews have been conducted far and wide, aiming to reflect the perceptions of the concerned communities at the micro level (see Badruddin et al., 1996). In light of that topical perspective, this paper has concisely conceptualized the apparent socio-cultural and ecologic-environmental effects of tourism as reflected from the perspectives of the members of the local society in Klang Valley region of Malaysia.

\section{STUDY AREA, METHODOLOGY AND DATA SOURCES}

This paper on tourism is based on direct observational information gathered through field study and empirical research methods, which is the result of an approved tourism project carried out in Klang Valley region of Kuala Lumpur, Malaysia spanning over 24 months from 2012-2014. The region explored in this research incorporates the entire urban and urban territories under the purview of Klang Valley areas of Kuala Lumpur and Selangor state. A survey was carried out among 200 families from two centrally placed urban groups, which are, for the most part, occupied by Malaysian citizens. These two communities include community members who live in Taman Impian Ehsan (or TIE), within the vicinity of UPM (Universiti Putra Malaysia), and Taman Midah (or TM) situated near Ampang, an extremely bustling business and diplomatic zone of Kuala Lumpur. Within the circumscription of greater Kuala Lumpur, both these communities are considered part of the Klang Valley region.

LOCAL PEOPLE'S PERCEPTION OF TOURISM IN MALAYSIAAs mentioned before, a survey was directed to unravel the mentality of the local individuals with respect to tourism and its related issues in Malaysia. The survey respondents were local people who hail from all three noteworthy ethnic groups (i.e., Malays, Chinese and Indians) living in the areas which demonstrate an unmistakable dominance of the Malays. They constitute 85 percent of the families met for this study. Since the Malays are overwhelmingly Muslims, their religious connection likewise indicates that they are followers of Islam. All of the 200 respondents in the study are well-educated, and a great number of them (no less than 71 percent) are additionally well-versed in English. This permits them to communicate with foreign tourists easily.

While getting some information about their impact on foreign tourists touring Malaysia, upwards of 92 percent of the inhabitants conceded that they are very much aware about their presence in this nation. In actuality, they are not completely discontented about their presence in Malaysia; rather, they have great affection and courtesy for them (tourists). Furthermore, the majority of the inhabitants in the Klang Valley deem it an extra blessing since it opens a new source for accumulating some additional cash. The local communities are highly appreciative of Klang Valley as a vacationing and tourist destination since it has a lot of appealing spots which may impress the guests. Simultaneously, they are also concerned and stressed on the social/cultural dissimilarities which regularly upset the sentiments of the local communities for which a large number of the respondents (58 percent) communicated their discontent, adding that tourism can negatively impact several aspects of their way of life, faith and culture.

It has been specified before that Malaysians, all in all, do not harbor much negative reaction to foreign guests and this has been demonstrated when we identify that 87 percent of the respondents from two groups at TIE and TM said that they like visitors coming to their nation. With a view to distinguish the reasons behind which they like foreigners visiting their nation, a progression of reactions arose. Among them are: (a) great increase in economic and financial exchanges; (b) Malaysia gets to be distinctly known to different people; (c) individuals can 
learn about foreign cultures, languages and get to know their way of life; (d) it is demonstrated that Malaysia is a favorable place to visit, etc.

Despite the positive reactions, a couple of respondents surmised that tourism has many unpleasant impacts on them, for example, (a) it has repercussions on national security, (b) visitors regularly make needless trouble for Malaysian populace by contributing immensely to destruction of the environment and ecological balance. They additionally speculated that foreign tourists are frequently involved in unlawful activities like drug trafficking, narcotics, violence, and there is a probability that local individuals may be distinctly afflicted to HIV/AIDS. Verifying these claims remains controversial since exposure to HIV/AIDS could be highly unlikely, and statistical databases corroborate that drug trafficking is not as frequent as claimed by the respondents since air and sea port authorities are ever-vigilant about it.

Table 1: Respondents' Views about Tourists and Visitors to Malaysia

\begin{tabular}{|c|c|}
\hline $\begin{array}{c}\text { Positive Responses received from } 184 \text { persons } \\
\text { from TIE and TM }\end{array}$ & $\begin{array}{c}\text { Negative responses received from } 16 \text { persons } \\
\text { from TIE and TM }\end{array}$ \\
\hline $\begin{array}{l}\text { Increase in economic transactions. } \\
\text { Learning of foreign languages and cultures. } \\
\text { Malaysia becomes known abroad which, is a sense } \\
\text { of pride. } \\
\text { Increase in local income } \\
\text { Proof that Malaysia is the right and conducive } \\
\text { place to visit. } \\
\text { Malaysia becomes known to others. } \\
\text { Visitors get to know Malaysian culture. } \\
\text { Economic boost through tourism. } \\
\text { Maintaining good relationship with other } \\
\text { countries. }\end{array}$ & $\begin{array}{l}\text { National security is affected } \\
\text { Tourists create unnecessary pressure on } \\
\text { population which contributes to the degradation of } \\
\text { the environment } \\
\text { Possibility of drug trafficking and possible } \\
\text { exposing of the local people to hidden HIV/AIDS. } \\
\text { Unaccustomed behavior of the tourists. }\end{array}$ \\
\hline
\end{tabular}

The people in the communities have thoughts regarding the acceptable and problematic aspects of tourism. At the point when distinguishing the praiseworthy side of tourism, the vast majority of them specified that it expands the stream of economy and at the same time extends the opportunity for work of the local communities. There are, be as it may, different perspectives saying that the local individuals are motivated to learn outsiders' culture and furthermore they have an inclination that interaction with more travelers in the nation demonstrates that Malaysia is acquainted with numerous countries of the world, their citizens, cultures, languages, and way of life. As to its utility, the members of the local society believe that it permits the general population to obtain skills related to foreign languages (particularly English) which makes them capable in English as they need to speak with the tourists and travelers in their everyday association. Table 2 shows the good sides of tourism as perceived by the respondents. 
Table 2: Favourable Effects of Tourism Perceived by the Respondents

Increases flow of the economy.
Increases job opportunities relating tourism for the Malaysians.
Introduces Malaysian science and technology at the outside and also it gets
exposed to the latest development of them in global context.
Malaysia can be introduced to the world in terms of their Muslim culture with
acceptable tolerance to modernity.
More exposure to other cultures.
The entry of foreign currency is also another positive aspect of tourism, from
economic point of view.
Malaysians become closer and intimate with the foreigners.
Learn and improve good speaking manners with internationals and also with those
people who are visiting Malaysia as tourists.
It teaches local people to be friendly and tolerant with outsiders.

While requesting the general population to demonstrate the problematic side of tourism, the respondents from the group communicated their disappointment specifying that because of the visitors' arrival, individuals can run the risk of being impacted negatively through bad qualities of foreign societies. The unpleasant side of tourism likewise incorporates an introduction to global violations including drug trafficking and empowering prostitution. The local communities regularly accuse the visitors of being self-important, discourteous and frequently indicate impoliteness to the local cultures. In particular, the pressure from widespread tourism propels the exhaustion of natural resources; numerous streets, expressways and highways are engineered superfluously having undesirable effects on the environment and affecting the ecological balance. Table 3 indicates the unfavorable sides of tourism as perceived by the respondents.

Table 3: Adverse Effects of Tourism Perceived by the Respondents

Possibility of being negatively influenced through social interactions with visitors.

The cultures of the tourists often affect the Malaysians.

Often committing criminal activities.

Malaysia is becoming crowded and thus gets more exposed to environmental pollution.

Price of basic necessities goes up.

Outsiders are often fund arrogant, insolent and disrespectful to the local norms and cultures.

Tourism may also allow drug trafficking and often encourage prostitution.

As the respondents conceded the financial effects of tourism, the local society has requested an understanding as to how they could build their financial earnings. A few particulars emerged from their perspectives. They noted that the tourists and travelers frequently buy numerous food items, sustenance related goods and services, and different things from the trivial merchants which is favorable for the local communities.

Tourism changes the life of the local society and thus, the respondents from the groups have been asked to indicate with reference to what kind of changes they for the most part notice because of progressing tourism in Malaysia. Various perceptions are mentioned that because of tourism numerous structures, shopping centers and malls are continuously being built with an inherent intention to pull in travelers from outside. Because of tourism, numerous tourist spots are regularly revamped and refined to make them alluring. They likewise feel that because of tourism the economy of the nation is quickly increasing and, concurrently, transport and correspondence framework is additionally enhanced to assist the international tourists in their ventures and visits. Despite the fact that these are obvious perceptions with respect to 
infrastructural improvement, members of the local society have other different perspectives also. They additionally said that because of tourism Malaysia gets to be distinctly known to others abroad and in the meantime, the nation is exposed to other cultures from which it stands to benefit if it wishes.

Interaction and exposure to other cultures is great from the social cooperation point of view, however, it has many stark contrasts which have been highlighted by the general population met in this study. The local communities frequently worry about the guests wearing nonIslamic attires which may impact and offend the locals. It is further expressed that being interested in the diversity, individuals regularly get acculturated which is not appropriate for a nation like Malaysia where individuals hold on to Islamic standards and Asian qualities. While getting some information about their impression of the foreign tourists and travelers to Malaysia, upwards of 92 percent of the occupants conceded that they are very much aware about their entry into this nation. Indeed, they are not completely troubled about their appearance in Malaysia, rather they find it advantageous to gain additional cash from this source. The local communities have high estimation of Klang Valley as it has a lot of alluring spots which may interest guests. In any case, they are additionally concerned and stressed about the social dissimilarities which regularly hurt the local communities for which a large portion of the respondents (58 percent -TIE ; 59 percent -TM) communicated their disappointment, saying that tourism influences numerous aspects of their life.

It has been said before that Malaysians, by and large, do not harbor much negative disposition to the outside tourists and travelers and this has been demonstrated when we observe that 87 percent of the respondents from two groups of TIE and TM specified that they like tourists and travelers visiting their nation. With a view to recognize the reasons why they like tourists and travelers coming into this country, a number of reactions have developed. These are: (a) bustling economic trades and financial transactions, (b) Malaysia gets to be distinctly known to different people, (c) individuals can learn foreign languages and get to know their way of life, (d) it is demonstrated that Malaysia is an appropriate and desirable destination to visit, etc.

In contrast, while requesting information about the negative aspects of tourism, the respondents from the group communicated their displeasure saying that because of tourists' entry, individuals have every possibility of being affected by foreign people and their cultures. The appalling aspects of tourism likewise incorporate an introduction to global wrongdoings having permitted the proliferation of drug trafficking and boost prostitution related activities. The study's respondents frequently accused the visitors of being haughty, impolite and regularly claim of tourists' insolence towards the local (Malaysian) culture. Above all, the pressure of tourism leads to widespread consumption of natural resources. Furthermore, numerous roads, expressways, highways and transportation facilities are built pointlessly having negative effect on the nature.

\section{CONCLUSION AND RECOMMENDATION}

This study on tourism is grounded on an empirical research conducted having procured primary data through quantitative and qualitative investigations of two urban communities located in Klang Valley, Kuala Lumpur, Malaysia.

It has been specified earlier that Malaysians in general do not apply many negative sentiments towards foreign guests and this has been demonstrated whereby 87 percent of the respondents from TIE and TM said that they like visitors coming to their country. With a view to understand the explanations behind this reason, an assortment of reactions arose. These are: (a) Bustling economic trades and financial transactions (b) Malaysia gets to be distinctly 
known to different people; (c) Individuals can learn foreign languages and get to know foreigners' way of life; (d) It is demonstrated that Malaysia is an appropriate and desirable destination to visit, etc. Furthermore, the survey respondents have thoughts regarding the positive and negative aspects of tourism. When they were asked to distinguish the elements of tourism, most of them said that it expands the stream of economy as well as the employment opportunities of the local denizens. At that point, there are different perspectives saying that the local individuals get exposure to different societies and furthermore they believe that the presence of more tourists and travelers in the nation shows that Malaysia has adaptive aquittance with numerous countries of the world. As to its utility, the individuals likewise surmise that it permits the general population to gain fluency and practice in conversing in foreign languages, particularly in English. This aids in their need to speak with the visitors in their everyday interactions.

On the other hand, when the respondents were asked to unravel the negative aspects of tourism, they communicated their disappointment specifying that because of tourists' presence, individuals have every possibility of being affected by remote societies. The awful elements of tourism additionally incorporate an introduction to global violations of drug trafficking and prostitution. The local communities likewise regularly accuse the visitors of being self-important, discourteous and frequently impolite to the native cultures. In particular, the pressure of widespread tourism propels the exhaustion of natural resources; numerous streets, expressways and highways are engineered superfluously having undesirable effects on the environment and ecological balance.

Results further showed that respondents positively perceived tourism as providing many economic and socio-political benefits, but many of them however, were ambivalent about some socio-cultural impact, increase of criminality and also in regard to environmental aspects of tourism. In many instances, they indicated the increased crime rate, air and noise pollution, traffic congestion and natural environment damages were found to be the negative aspects of tourism impact.

On the other side of the story, it is extremely significant for Malaysia to gain local community support for tourism development. This is because of the reason that a huge amount of the country's income in Malaysia indeed at present, comes from tourism. Accordingly, many national tourism programs in the title like, "Visit Malaysia Year", "Beautiful Malaysia", "Malaysia, truly Asia", among others, are showcased the better side of the country's effort in attracting visitors and tourists in Malaysia. Tourism development therefore, is very much important in this respect. Contextually, Andereck and Nyaupane (2011) have reminded us saying that community support is vital components in achieving successful tourism industry. This research thus is in the view that community's positive perceptions toward tourism and tourists in Malaysia may further support for future tourism development. It is suggested that the community members should actively participate in tourism activities and provide supports for tourism development. This mutual community relationship may further bring in a better quality of life among members of that community and their environment. Failure to take an integrated and holistic approach in developing tourism agenda will only expose both sides the community and country - to a negative socio-cultural and environmental impact. Therefore, it is believed to have some restrictions on several views such as a responsible tourism practice that put emphasis on human's quality of life. 


\section{Endnotes}

1. In tourism literature, the terms travel and tours are often used interchangeably to provide a synonymous meaning which encompasses a temporary movement of the persons from his/her immediate residence and communities where he/she stays permanently and thus gets involved on a daily work-environment moving to a place which is different from it (see Chadwick 1994).

\section{References}

Andereck, K.L, and Nyaupane, G.P. (2011). Exploring the Nature of Tourism and Quality of Life Perception among Residents. Journal of Travel Research, 50, 248-260

Badri bin Haji Masri (1991): "The growth and prospects of Domestic Tourism" In International Conference on Tourism: Development Trends and Prospects in the 90's. Organized by the Department of Urban and Regional Planning. Faculty of Built Environment. Universiti Teknologi Malaysia, 16 to 18 September, 1991. PP-1-10.

Badruddin, M. B. Som, M., Puad, A., Jusoh, J., and Kong, Y. W. (2006). Island Tourism In Malaysia The Not So Good News. A paper published by the Department of Building and Planning. Penang: Universiti Sains Malaysia. pp 12121219.

Chadwick, R. (1994). 'Concepts, definitions and measures used in travel and tourism research' in J.R.Brent Ritchie and G. Goeldner (eds). Travel, Tourism and Hospitality Research: A Handbook for Managers and researchers. New York: Wiley. P-65.

Mathieson, A., and Wall, G. (1989). Tourism, Economic, Physical and Social impacts. London: Longman Scientific and Technical.

Mieczkowski,Z.T.(1981). Some Notes on Geography of Tourism: A Comment. Canadian geographer.25: pp 186-191.

McColl,S.F. and Martin, S.R. (1994). Community Attachment and Attitudes toward Tourism Development. Journal of Travel Research, 32(3), pp29-34. 